Article

\title{
Combined Heat and Power from Municipal Solid Waste: Current Status and Issues in South Korea
}

\section{Changkook Ryu ${ }^{1, *}$ and Donghoon Shin ${ }^{2}$}

1 School of Mechanical Engineering, Sungkyunkwan University, Suwon 440-746, Korea

2 School of Mechanical Systems Engineering, Kookmin University, Seoul 136-702, Korea; E-Mail: d.shin@kookmin.ac.kr

* Author to whom correspondence should be addressed; E-Mail: cryu@ @me.skku.ac.kr; Tel.: +82-31-299-4841; Fax: +82-31-290-5889.

Received: 26 October 2012; in revised form: 24 November 2012 / Accepted: 24 December 2012 / Published: 27 December 2012

\begin{abstract}
Municipal solid waste (MSW) is an important energy resource for combined heat and power (CHP) production. This study summarized an overview of CHP by MSW to energy (WtE) plants in South Korea and discussed the issues related to energy efficiency improvement. Given the dominant housing culture of apartment living in South Korea, the primary energy output of WtE plants has been for district heating. In 2010, approximately half of the 51 large $\mathrm{WtE}$ plants were $\mathrm{CHP}$, while the rest produced heat. Power generation in the WtE CHP plants was estimated to be only 3.65\% of the thermal input, while heat production was $60.79 \%$. The R1 efficiency when compared to that in Europe was similar for the CHP plants and higher for heat-only plants. Improving power generation efficiency is required for new power plants producing steam at pressures higher than the current level of 20-30 bar. Over ten of the existing plants needed to increase their energy efficiency by installing new equipment such as steam turbines for excess steam. Finally, transboundary centralization of WtE plants between neighboring local authorities is essential for heat utilization since many existing small-scale plants ( $<50 \mathrm{t} /$ day capacity) do not recover heat.
\end{abstract}

Keywords: combined heat and power; energy efficiency; municipal solid wastes; incineration; waste to energy 


\section{Introduction}

Waste management with a low environmental impact is an essential element of modern society. The prioritization of waste management is expressed as the well-known hierarchy of "prevention", "reuse", "recycling", "recovery" and "disposal". Waste to energy (WtE) is the recovery of the energy content, preferably for non-recyclable wastes. This is usually achieved by combustion of the waste to release its chemical energy and then transferring this energy to water/steam in a boiler to produce heat and/or power. Compared to commercial fuels, municipal solid wastes (MSW) are low quality fuels due to their low energy content, their large variations in fuel properties and the high content of chlorine and heavy metals. However, there are established technologies available for WtE such as grate-type combustion, fluidized bed combustion and pyrolysis/ash-melting [1]. Other conversion technologies are also available to increase the fuel quality of wastes and their flexible use, such as production of solid recovered fuel (SRF) and gasification [2,3]. After recovering heat, the solid residue (bottom ash and fly ash) can be utilized as feedstock for construction [4] or safely disposed of with a minimal environmental impact [5].

One important feature of $\mathrm{WtE}$ is that it displaces the consumption of fossil fuels for heat and power production. Moreover, MSW contains biogenic fractions such as paper and wood, and the energy produced from those is carbon-neutral, thereby reducing greenhouse gas emissions [6]. Moreover, in many countries, WtE has been an important source of renewable energy [7-9].

Unlike a fossil-fuel-fired power plant, a WtE plant is usually located close to its energy source, which is often a populated urban or industrialized area. Due to this reason, WtE plants can operate in a CHP mode, that is, the residual heat in the steam after power generation is exported to a district heating $(\mathrm{DH})$ system or to nearby heat demanding industries as process heat $(\mathrm{PH})$. Although power generation efficiency is lower than typical power plants with a steam turbine $(35 \%-45 \%)$, an ideal WtE plant for CHP can achieve overall energy (power and heat) efficiencies as high as $85 \%$ of the energy content in MSW [10]. Development of a district energy network to fully utilize heat from WtE together with other renewable energy sources can greatly lower the carbon emissions, as reported for the case of Sheffield, UK [11,12].

In some cases, however, achieving a high energy efficiency of $\mathrm{WtE}$ is not practical due to various technical and non-technical reasons. The design and operation of a WtE plant is determined primarily by the amount of MSW to be treated, not by energy demand. Therefore, utilization of the heat produced from a WtE plant needs to be considered from the planning stage of a new installation. In particular, small-scale plants in rural areas often do not have a sufficient enough need for heat, therefore in these instances installing heat recovery facilities significantly increases the capital and operation costs. Without energy recovery, waste incineration is only for easy disposal of wastes by landfill of ashes after volumetric reduction and removal of biodegradable fractions. In order to differentiate energy recovery from waste disposal, the European Union (EU) introduced a revised Waste Framework Directive (WFD, 2008/98/EC) in 2008 [13]. In the Directive, the energy efficiency of a WtE plant is evaluated using the "R1 formula", which is the ratio of net energy output over input with equivalence factors of 2.6 multiplied for electricity production and 1.1 for heat production. New or recent WtE installations (permitted after 31 December 2008) with an R1 efficiency $\geq 0.65$ can be classified as recovery action, while 0.60 is applied to older installations. Grosso et al. [14] reported 
that European WtE plants in 2004 had an average R1 efficiency of 0.71 for CHP, 0.49 for electricity and 0.64 for heat producing plants.

WtE of MSW plays a crucial role in renewable energy production in Korea. As a country with limited natural resources, Korea imports about $98 \%$ of its energy sources from abroad [15]. Moreover, in 2010 , WtE by incineration was $11.8 \%$ of total "new and renewable" energy production, while wind power and photovoltaics were $2.5 \%$ each [16]. Recognizing the importance of MSW for WtE, in 2008 the Korean government announced a new "Waste to Energy Strategic Plan" [17], which aims to increase energy recovery and utilization for all available non-recyclable wastes from the current level of $32 \%$ to $57 \%$ by 2012 , and to $100 \%$ by 2020 . This is one of essential elements of the National Energy Plan also announced in 2008 [18], which set ambitious national targets and introduced many new measures for sustainable development. These targets include increasing renewable energy production to $11 \%$ of the national total by 2030 .

This paper reviews the current status of WtE for MSW in South Korea and analyzes the energy efficiency of large WtE plants. Raw data for analysis was collected from annual summary reports of WtE operators and official documents published by the Korean Government. The energy efficiency of the WtE plants was compared to that of European plants based on the R1 formula of the EU WFD. Based on these results, energy efficiency improvement issues are discussed.

\section{Management of MSW in South Korea}

Table 1 presents an overview of MSW management in Korea from 1997 to 2010 [19]. In 1995, the enforcement of regulations regarding the use of disposal bags for household waste has since resulted in a steady generation of MSW of approximately $50 \mathrm{kt} /$ day or $1 \mathrm{~kg} /$ day/capita. In that period, the proportion of wastes recycled drastically increased from $29.0 \%$ in 1997 to $60.5 \%$ in 2010 due to the high level of segregation of recyclable wastes from households. This led to an insufficiency of MSW for incineration in some existing plants, which is discussed in Section 4.4. In the same period, however, the amount of waste incinerated increased three-fold from $7.1 \%$ in 1997 to $21.6 \%$ in 2010 . High recycling rates were beneficial in raising public acceptance for incineration, since the public realized that it is applied for non-recyclable wastes they disposed in dedicated bags. The segregation of food waste and corresponding increase in the heating value of MSW also shifted the public perception and waste management policy for incineration from disposal action to energy recovery. As a result, landfill waste decreased from $63.9 \%$ to $17.9 \%$. Compared with the average of 27 European countries [20], the proportion of recycling is $20 \%$ higher although incineration levels are similar. Overall, MSW in South Korea is managed reasonably well.

Figure 1 illustrates the trend in the fuel properties and the material breakdown of MSW averaged for the monthly analytical data measured at 40 large WtE facilities in Korea [21]. The error bars for the lower heating value (LHV) in Figure 1a represent the standard deviation. The LHV of MSW increased from $8.16 \mathrm{MJ} / \mathrm{kg}$ in 2002 to $11.92 \mathrm{MJ} / \mathrm{kg}$ in 2011 , due to a gradual decrease in moisture content from $46.8 \mathrm{wt} \%$ to $33.2 \mathrm{wt} \%$. The decrease in moisture content is largely attributed to the reduction in food waste, which has very high moisture content. Given the separate collection of food waste enforced in 2005, the proportion of food waste decreased from $36.1 \mathrm{wt} \%$ in 2002 to $13.0 \mathrm{wt} \%$ in 2011 (Figure 1b). This also led to a decrease in the bulk density from $0.292 \mathrm{t} / \mathrm{m}^{3}$ to $0.218 \mathrm{t} / \mathrm{m}^{3}$. On a dry basis, the ratio 
of combustibles to ash content was steady at about 4.8. The elemental composition of the combustible fraction was estimated to be $60.7 \% \mathrm{C}, 8.4 \% \mathrm{H}, 29.0 \% \mathrm{O}, 0.8 \% \mathrm{~N}, 0.1 \% \mathrm{~S}$ and $1.0 \% \mathrm{Cl}$ on a dry-ash-free basis [22]. In 2011, paper (33.9 wt \%) and plastics (26.4 wt \%) were the main constituents of household wastes, which provide most of the heating value.

Table 1. Summary of MSW management in South Korea.

\begin{tabular}{llcccccc}
\hline & Year & $\mathbf{1 9 9 7}$ & $\mathbf{2 0 0 0}$ & $\mathbf{2 0 0 3}$ & $\mathbf{2 0 0 7}$ & $\mathbf{2 0 1 0}$ & EU27 2010 [20] \\
\hline \multirow{2}{*}{ Generation } & (t/day) & 47,896 & 46,438 & 50,736 & 50,346 & 49,159 & \\
& (kg/day/capita) & 1.04 & 0.99 & 1.06 & 1.02 & 0.96 & 1.38 \\
\hline \multirow{2}{*}{ Management } & Recycling (\%) & 29.0 & 41.3 & 45.2 & 57.8 & 60.5 & 41.1 \\
& Incineration (\%) & 7.1 & 11.7 & 14.5 & 18.6 & 21.6 & 21.6 \\
& Landfill (\%) & 63.9 & 47.0 & 40.3 & 23.6 & 17.9 & 37.3 \\
\hline
\end{tabular}

Figure 1. (a) Components and LHV of MSW and (b) material breakdown in 2002-2011 analyzed at large incineration plants.

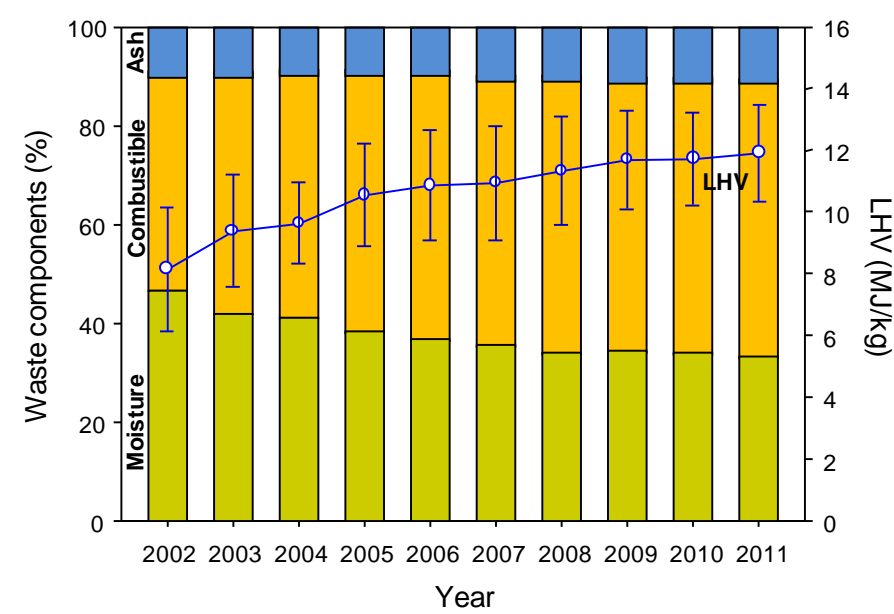

(a)

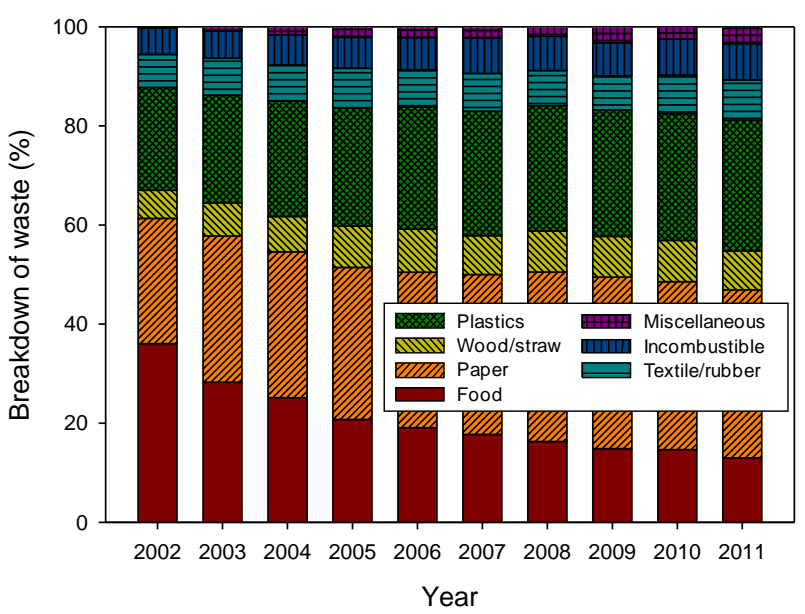

(b)

\section{Energy production and Efficiencies of WtE from MSW in Korea}

\subsection{Energy Production from MSW}

As of 2011, 53 large WtE plants for MSW are in operation in Korea with a capacity ranging from 50-900 t/day [23]. Plants with a capacity larger than 300 t/day typically comprise of two or three identical units each with a capacity of $100,150,200,300$ or 400 t/day. The total capacity of the plants is 14,192.5 t/day. Among them, 46 plants incorporate grate type furnaces, three fluidized bed and four pyrolysis/melting type. These plants burned $3439 \mathrm{kt}$ of wastes in 2010, which represents $88.7 \%$ of MSW incinerated in the country. Small-scale ( $<50$ t/day) plants located in rural areas or in small cities treated the remaining MSW.

Figure 2 shows the amount of heat and power produced from WtE plants since 2002 [21]. The heat recovered by steam was used mostly as heat. On-site heat consumption was the largest in 2002, equivalent to $57 \%(7482 \mathrm{TJ})$ of total heat use $(13,063 \mathrm{TJ})$. This heat was used for various purposes such as reheating flue gas for selective catalytic reactors and the prevention of white smoke, preheating 
of combustion air, and on-site hot water supply. The amount of on-site heat consumption was steady throughout the period despite the growth in the number of plants, which was due to the efforts to efficiently utilize the heat at the plants. The amount of heat exported for $\mathrm{DH}$ or $\mathrm{PH}$ exceeded the on-site consumption in 2006 and continued to increase. The fraction of heat exported for $\mathrm{PH}$ is small compared to $\mathrm{DH}$, which was done at eight out of 51 plants in 2010. It is important to note that Korea has a unique housing culture in that apartments are the main residential form in urban areas. According to the 2010 national population and housing census, $47.1 \%$ of all homes were apartments [15]. Therefore, it is relatively easy to install district heating systems that supply heat and hot water in an apartment district. The heat exported to DH is sold typically to public DH corporations at $27 \%$ of the customer price [21]. The heat used at subsidiary facilities refers to hot water or steam for swimming pools or food waste treatment facilities collocated with a WtE plant, which was at 16 out of 51 plants in 2010. In 2011, power generation was very small compared to that of heat production (943 TJ) and was used mostly on-site. However, electricity export to grid significantly increased from $11 \mathrm{TJ}$ in 2002 to $302 \mathrm{TJ}$ in 2011, representing about a third of all electricity produced. Overall, heat is the dominant form of energy produced from WtE plants in Korea due to the large demand for heat while efficient power generation requires much higher capital costs. Details of technical data including energy efficiencies and steam pressures are discussed later.

Figure 2. Energy production and use at WtE plants in 2002-2011.

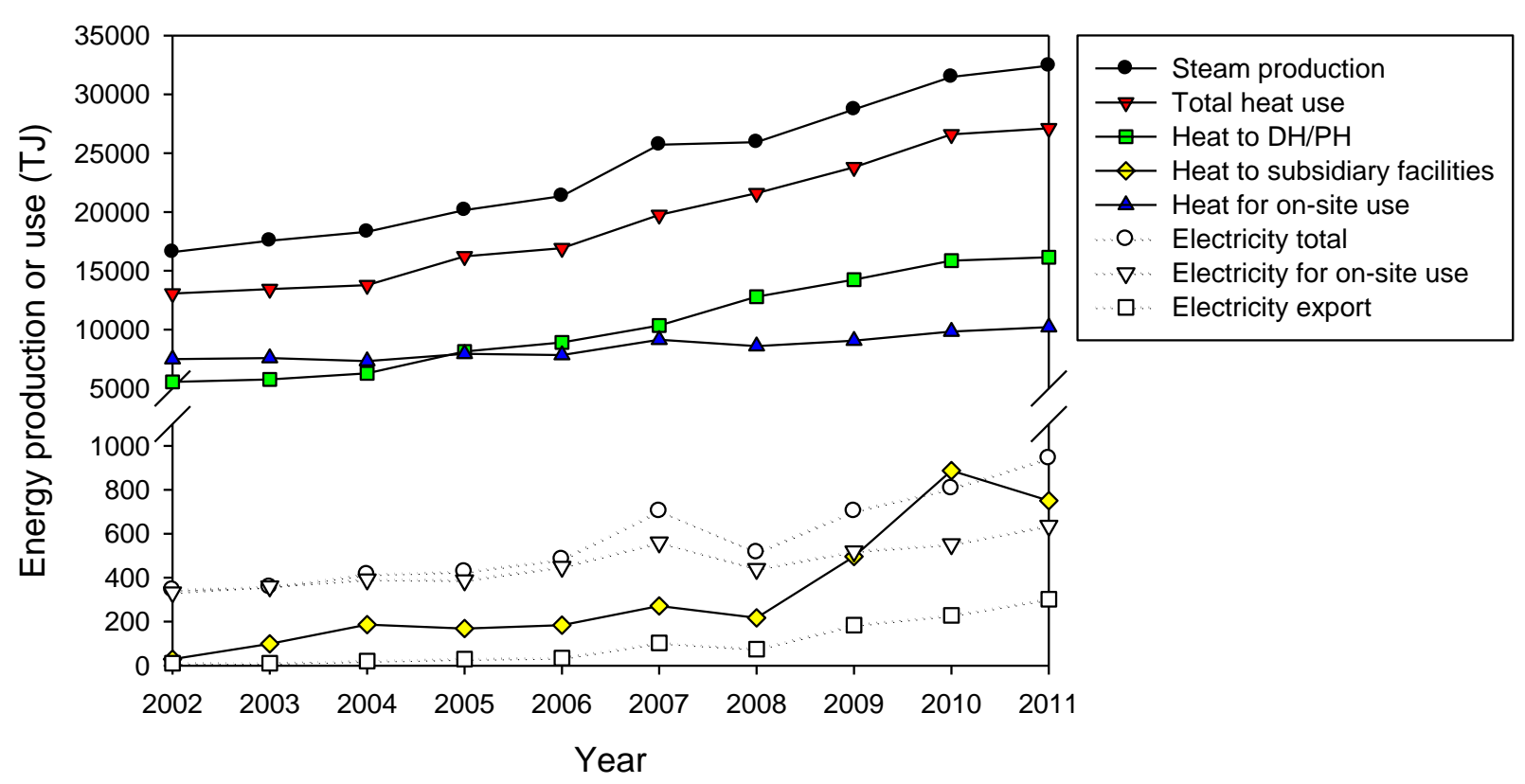

\subsection{Korean WtE Energy Efficiencies}

Table 2 lists the status and efficiencies of energy production in selected years by large WtE plants for which detailed technical data is available [21,23]. The number of plants increased significantly in 2002-2010, but the ratio between CHP and heat-only remained similar. Waste throughput per site is larger for CHP plants because recently installed CHP plants have larger capacities (100-300 t/day) than the heat-only plants (mostly 50 t/day) located at small cities. 
Table 2. Summary of status and gross efficiency for heat and power production in 2002 and 2010 from WtE plants.

\begin{tabular}{llcc}
\hline & \multicolumn{1}{c}{ Year } & $\mathbf{2 0 0 2}$ & $\mathbf{2 0 1 0}$ \\
\hline Combined Heat & Number of plants & 13 & 25 \\
and power & Annual waste throughput $(\mathrm{kt})$ & 1,307 & 1,899 \\
& Thermal input of MSW $(\mathrm{TJ})$ & 10,662 & 22,265 \\
& Heat production efficiency, $\eta_{\text {heat }}(\%)$ & 63.1 & 60.8 \\
& Power generation efficiency, $\eta_{\text {power }}(\%)$ & 3.2 & 3.6 \\
\hline Heat-only production & Number of plants & 14 & 26 \\
& Annual waste throughput $(\mathrm{kt})$ & 867 & 1,494 \\
& Thermal input of MSW $(\mathrm{TJ})$ & 7,073 & 17,511 \\
& Heat production efficiency, $\eta_{\text {heat }}(\%)$ & 89.2 & 74.9 \\
\hline
\end{tabular}

The energy efficiencies in Table 2 were calculated, based on the total heat and electricity use (Figure 2) and the average LHV (Figure 1a). The gross efficiencies for heat production ( $\eta_{\text {heat }}$ ) and power generation $\left(\eta_{\text {power }}\right)$ are defined, respectively, as follows:

$$
\begin{gathered}
\eta_{\text {heat }}(\%)=100 \times E_{\text {heat }} / E_{\text {waste }} \\
\eta_{\text {power }}(\%)=100 \times E_{\text {elec }} / E_{\text {waste }}
\end{gathered}
$$

where $E_{\text {waste }}$ refers to the thermal input calculated by waste throughput times the LHV. $E_{\text {heat }}$ and $E_{\text {elec }}$ represent total heat use and power generation including on-site consumption, respectively. Table 2 shows that $\eta_{\text {heat }}$ and $\eta_{\text {power }}$ in 2010 were $60.8 \%$ and $3.6 \%$, respectively. The net power generation became as low as $1.0 \%$ of the thermal input, which is for the electricity exported to grid. Surprisingly, the overall efficiencies were lower than in 2002. This is due to a large uncertainty in the LHV of the input wastes, which is always an issue due to its heterogeneous nature. Detailed analysis for individual WtE plants revealed that the values of LHV in 2002 were significantly underestimated. Figure 3 plots the boiler efficiency (= heat output as steam / $\mathrm{E}_{\text {waste }}$ ) vs. LHV for individual plants in 2002 and 2010. If the LHV is underestimated, it leads to an overestimation of the boiler efficiency. In 2002, 14 out of 27 plants are above $100 \%$, which is thermodynamically impossible. One plant in Figure 3 a even has a boiler efficiency estimated as high as $169 \%$. The actual boiler efficiency is limited by the residual enthalpy in flue gas at the boiler exit (typically at $150-200{ }^{\circ} \mathrm{C}$ ), radiation loss and unburned carbon. The practical upper limit of boiler efficiency would be about $85 \%$. The highest boiler efficiency of WtE plants in Europe was $84.2 \%$ with average of $81.2 \%$ [24]. Figure 3a also shows that the plants that reported a LHV lower than the average tended to have a higher efficiency and vice versa. In 2010 (Figure 3b), three of those are still above 100\%. Note that in 2007 there were eight plants with efficiencies above $100 \%$ by the same analytical method [22]. This suggests that the uncertainty involved in the analysis of waste properties was considerably reduced in 2010. Overall, it is not very reliable to analyze the energy efficiencies using the LHV at this stage. However, it would be reasonable to say that the efficiencies in Table 2 for 2010 would be close to the true values. 
Figure 3. Steam production efficiency based on the reported LHVs for WtE plants in (a) 2002 and (b) 2010 .

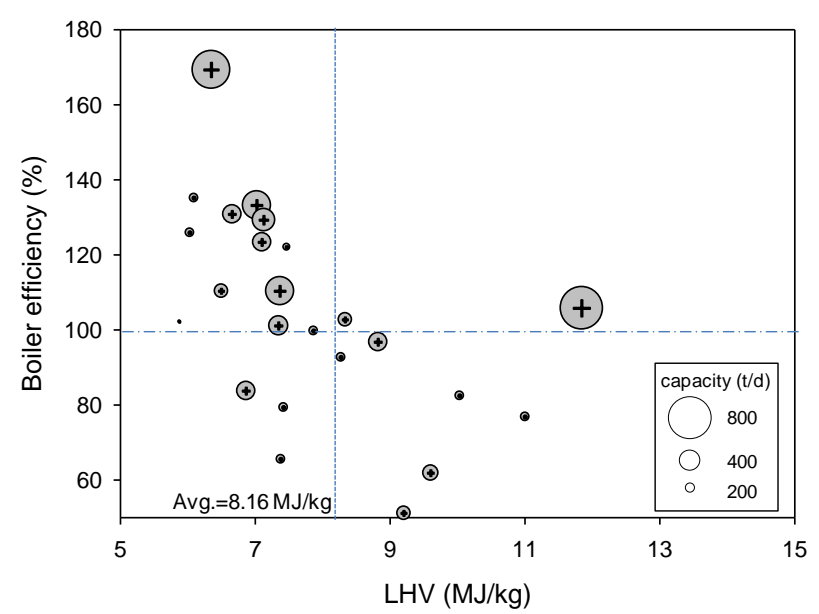

(a)

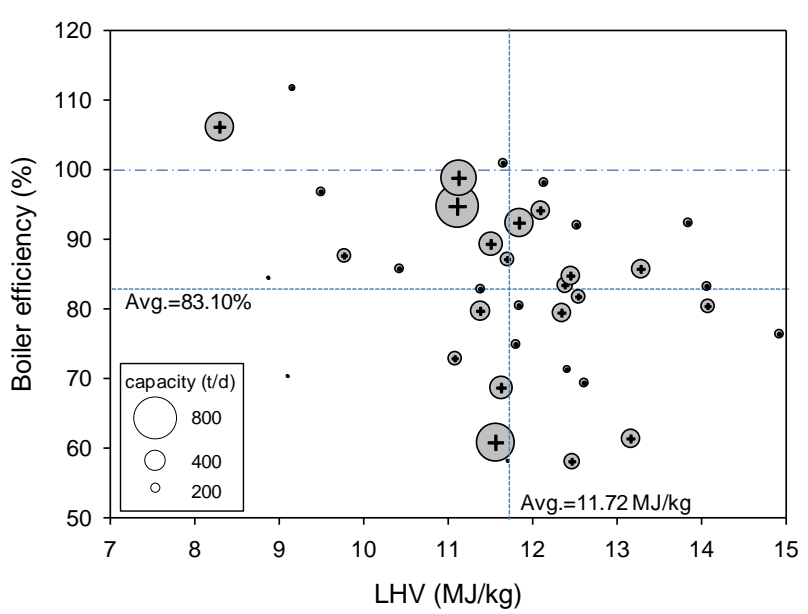

(b)

Figure 4 shows R1 efficiencies of EU WFD evaluated for 37 large WtE plants in Korea using the operation data in 2010 for comparison with EU WtE plants. R1 efficiency in WFD is defined as:

$$
\begin{aligned}
& \mathrm{R} 1 \text { efficiency }=E_{\text {prod }}-\left(E_{\text {fuel }}+E_{\text {import }}\right) / 0.97\left(E_{\text {waste }}+E_{\text {fuel }}\right) \\
& \text { where } E_{\text {prod }}=1.1 E_{\text {heat }}+2.6 E_{\text {elec }}
\end{aligned}
$$

For the energy produced ( $\left.E_{\text {prod }}\right)$, an equivalence factor of 1.1 is multiplied for heat produced ( $\left.E_{\text {heat }}\right)$ and 2.6 for electricity $\left(E_{\text {elec }}\right)$ each of which is based on the average efficiency in European power plants $(38 \%)$ and heat plants $(91 \%)$ [25]. Energy output excludes the input from other fuels $\left(E_{\text {fuel }}\right)$ and imported ( $\left.E_{\text {import }}\right)$. A factor of 0.97 is multiplied to the thermal input for waste $\left(E_{\text {waste }}\right)$ and other fuels $\left(E_{\text {fuel }}\right)$ to account for the energy loss due to bottom ash and radiation during thermal conversion. In the calculation, the use of auxiliary fuels for $E_{\text {fuel }}$ and $E_{\text {import }}$ in individual plants was included with a LHV of 39.9 MJ/m for $\mathrm{LNG}$ and 36.0 MJ/L for light fuel oil.

Figure 4. R1 efficiencies of WtE plants in Korea in 2010.

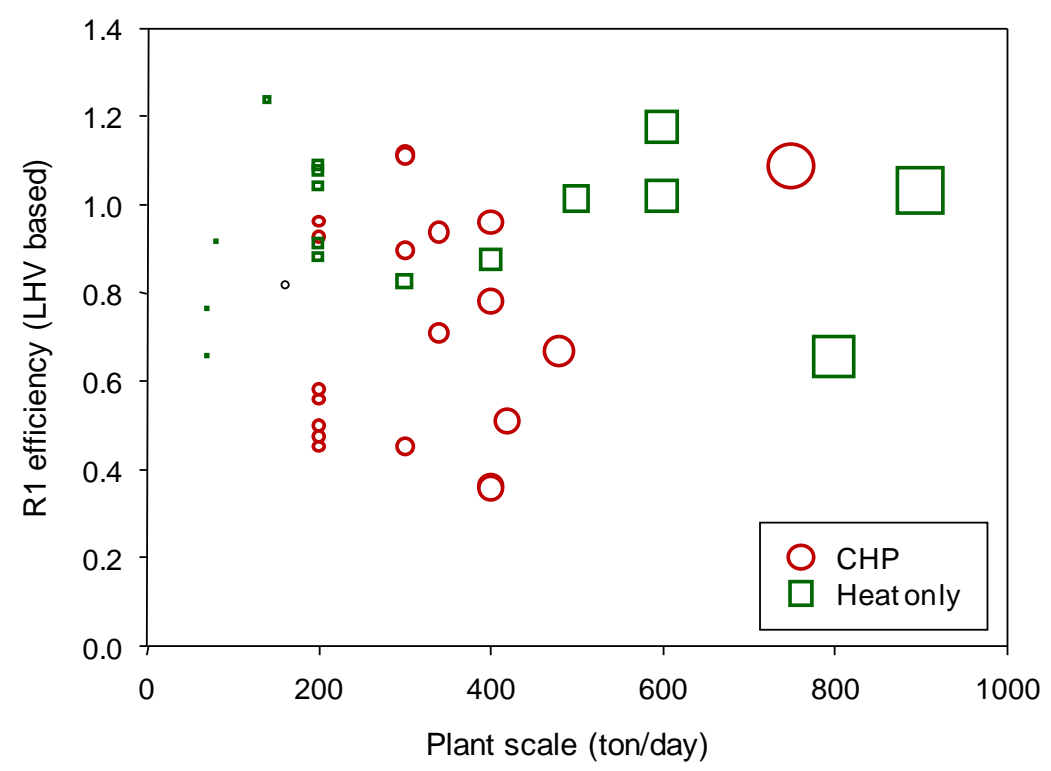


In Figure 4, the average R1 efficiency of $21 \mathrm{CHP}$ plants is 0.716 , which is comparable to those in Europe (0.71) [14]. The number of plants under the threshold of 0.6 is 9 , in which the heat produced is used mostly on-site including three plants without any heat export to DH or PH. Electricity producing plants in the EU have been reported to have an average R1 efficiency of 0.49 [14]. For 16 plants producing only heat, the R1 efficiency (0.936) is much higher than that of the EU (0.64). This is because plants export all extra heat to $\mathrm{DH}$ or PH. Regarding the uncertainties in LHV analysis, the same calculation was carried out for $E_{\text {waste }}$ based on steam output instead of LHV. Assuming that steam output is $83.1 \%$ (average boiler efficiency in Figure 3b) of thermal input, the average R1 efficiency becomes 0.737 for CHP plants and 0.905 for heat producing only plants. Therefore, the results are overall similar between the two approaches.

\section{Issues of WtE in Korea}

\subsection{Increase in $L H V$}

Most existing WtE plants in Korea were designed for a reference LHV of $7.1 \mathrm{MJ} / \mathrm{kg}(1700 \mathrm{kcal} / \mathrm{kg})$ with operational limits ranging from 4.2 to $10 \mathrm{MJ} / \mathrm{kg}(1000-2400 \mathrm{kcal} / \mathrm{kg})$. Due to the continuing increase in the LHV of wastes, however, the present values are well over the design limits for many plants. This has caused serious operation problems. For example, excessively high temperature damages furnace walls and the increased need for maintenance lowers plant availability. In addition, waste throughput is kept low in order to control for heat input to the boiler. Only several plants built recently can properly treat the wastes with a high LHV. Therefore, retrofit of the furnace and boiler is required for existing plants with a sufficient life-time remaining. A successful example for this is the plant at Yangchun, Seoul (operated by Hankook Seghers Co. Ltd., Seoul, Korea; two units of 200 t/day capacity; commissioned in 1996) which replaced the existing refractory wall in the lower part of the furnace with membrane wall to increase the heat absorption of the boiler. Similar to most old plants, the refractory wall in the lower furnace was originally designed to achieve quick ignition and good burn-out of the waste with high moisture content. The heat recovery by membrane walls started from the level of secondary air injection in the mid-level of the furnace. Installing the membrane wall in the lower part of the furnace in 2010 enabled $20 \%$ increase in the waste throughput for a reference LHV of $11.3 \mathrm{MJ} / \mathrm{kg}(2700 \mathrm{kcal} / \mathrm{kg})[26]$.

\subsection{Steam Pressure and Power Generation Efficiency for a New Plant}

Power generation efficiency of Korean WtE CHP plants in 2010 was very low with a gross value of $3.65 \%$ and net $1.03 \%$. This was due to low steam pressures in boilers. Table 3 details the technical data for steam produced at four representative WtE plants. Most large CHP or heat-only plants have designed steam pressures of $16-21$ bar with temperatures of $200-240{ }^{\circ} \mathrm{C}$ which are close to saturated steam. The highest steam pressure is about 40 bar with a temperature of $400{ }^{\circ} \mathrm{C}$ at two heat-only plants located in Seoul (Gangnam and Nowon). The steam is exported to a nearby CHP facility that supplies heat for district heating. A recently built plant in Ichon has the highest steam pressure of 30 bar for WtE CHP in Korea. Small-scale plants such as the one in Nonsan, have a steam pressure of 7-10 bar and temperature $160-183{ }^{\circ} \mathrm{C}$ for heat production. The reason for such low steam pressures and temperatures 
is due to the large heat demand for DH and also the minimization of corrosion in heat exchangers. In contrast, WtE plants in Japan commissioned since the year 2000 mostly have steam temperatures around $400{ }^{\circ} \mathrm{C}$ and power generation efficiency as high as $23 \%$ [27]. Most plants in the EU also have steam temperatures of about $400{ }^{\circ} \mathrm{C}$ and above with steam pressures of about 40 bar [10,28]. A state-of-the-art WtE plant at the Netherlands achieves $30 \%$ of net power generation efficiency with a steam pressure of 125 bar and temperature $440{ }^{\circ} \mathrm{C}$ [29]. Therefore, increasing the power generation efficiency with higher steam pressures is essential for new WtE installations in Korea. The configuration of steam pressures, turbines and energy efficiencies for WtE has been reviewed by Pavlas et al. [30].

Table 3. Design properties of steam at four representative WtE plants.

\begin{tabular}{lccccc}
\hline Plant (City) & Gangnam, Seoul & Jeonju & Ichon & Nonsan \\
\hline \multicolumn{2}{l}{ Capacity (t/h) } & $300 \times 3$ units & $200 \times 2$ units & $150 \times 2$ units & $50 \times 1$ units \\
\hline $\begin{array}{l}\text { Design } \\
\text { properties }\end{array}$ & $\begin{array}{l}\text { Pressure (bar, } \\
\text { gauge) }\end{array}$ & 40 & 21 & 30 & 7 \\
of steam & Temp $\left({ }^{\circ} \mathrm{C}\right)$ & 400 & 216 & 300 & 170 \\
& Flow rate $(\mathrm{t} / \mathrm{h})$ & 131.4 & 59.3 & 60.6 & 6.6 \\
\hline Energy production & Heat-only & CHP & CHP & Heat-only \\
\hline Note & Heat exported to & Typical at large- scale plants & & Typical at \\
& CHP system & for CHP or heat-only & & small scales \\
\hline
\end{tabular}

\subsection{Improving the Energy Efficiency at Existing Plants}

Energy efficiency improvement of existing plants can be achieved by installing a steam turbine or by installing an additional heat export system to a nearby site if the demand for heat exists. Another way is to co-locate new waste management facilities with heat demand (e.g., food waste treatment or drying of sewage sludge for fuel production) at an existing WtE plant. Reduction in consumption of auxiliary fuels and electricity is also necessary to improve efficiency. However, such measures are appropriate only for plants with excess heat and sufficiently long life-times. According to study by the Korean Ministry of Environment [31], installing a steam turbine for power generation was economically feasible in nine plants with a capacity larger than 50 t/day and five smaller plants. These plants had over six years of life-time remaining and most had $>3 \mathrm{t} / \mathrm{h}$ of excess steam not utilized. The energy efficiency of these plants is expected to increase since the government has initiated several projects to install additional energy recovery facilities.

\subsection{Transboundary Centralization of a WtE Plant}

Currently, there are over 100 incineration plants with capacities smaller than 50 t/day across Korea. These small-scale plants are usually located in rural areas and do not recover heat. Instead, water is sprayed at the furnace exit to quench the combustion gas for prevention of PCDD/Fs formation. The main reasons for not recovering energy from wastes are: (i) to lower the capital costs; (ii) nearby heat demanding sites are not available; and (iii) difficulties in maintaining continuous operation. In order to increase energy recovery from small-scale plants, governmental policy should include transboundary centralization of new WtE plants between neighboring local authorities. One effective approach would 
be to provide government subsidies to cover the capital costs of centralized WtE plants with heat recoveries above a certain thresholds such as the R1 formula of the EU WFD. In order to be eligible for the subsidies (30\%-50\% of capital costs), the current legislation for waste management in Korea requires a new WtE plant to have energy recovery/utilization and transboundary treatment of MSW. However, no thresholds are set in the legislation on the efficiency of energy recovery.

Old WtE plants also require transboundary approach of MSW management to increase plant availability and energy production. Good examples can be found in Seoul. Among four plants in the capital, three were built in 1996-2001 only for the MSW generated from the districts where they are located. The plants had a waste throughput ranging only from $20 \%$ to $30 \%$ of the capacity until 2006 , due to a decrease in the amount of waste as a result of increased recycling rate and separation of food waste from combustibles. However, the plant availability has increased to about $60 \%-80 \%$ since transboundary waste treatment began in 2007 [26]. Such a progress was possible by raising public acceptance on incineration after improving the removal efficiency of PCDD/Fs in the plants to a level of $0.01 \mathrm{ng}-\mathrm{TEQ} / \mathrm{m}^{3}$ (average of $0.003 \mathrm{ng}-\mathrm{TEQ} / \mathrm{m}^{3}$ in 2011), far below the emission regulation $\left(0.1 \mathrm{ng}-\mathrm{TEQ} / \mathrm{m}^{3}\right)$. The latest plant (Mapo) in Seoul was built in 2005 with a planning for transboundary waste treatment. The four plants currently treat MSW from 22 districts out of 25 in the capital.

\subsection{Renewable Energy from WtE}

International standards for renewable energy such as that of EU Renewable Energy Directive (2009/28/EC) differentiate biogenic fractions of MSW from non-biogenic fractions. However, the energy from MSW in Korea is classified as "new and renewable energy", together with other wastes such as residual gas from oil refineries, waste tires, waste woods and integrated gasification combined cycle (IGCC) of coal. Although the statistics of MSW includes the breakdown of materials in MSW (as shown in Figure 1b), no standard has yet been established to estimate the energy and $\mathrm{CO}_{2}$ emission from non-biogenic and biogenic fractions. Table 4 summarizes a study by the Korea Energy Economics Institute that estimated the proportion of energy from biogenic fractions of MSW for two cases of LHV. Based on the US Energy Information Administration (EIA) method [32], about $40 \%$ of energy can be classified as renewable. Note that the component of textile/leather (TL) is classified as biogenic in the EIA method for simplification, although it may include a certain fraction of synthetic materials. In contrast, the European standard (EN 15440) for manual sorting assumes $50 \%$ biogenic for fabric and $80 \%$ for leather [33]. The error involved in such simplifications could be significant. Therefore, further investigations are required to determine the LHV and biogenic fractions of individual materials for domestic MSW in Korea [24]. Recognizing the renewable portion of power from MSW, raising its

price could be an effective way to achieve higher power generation efficiency from WtE plants. The current incentive on the electricity from a WtE plant is not significant as it is sold at a system marginal price (SMP, average of about $120 \mathrm{KRW} / \mathrm{kWh}$ in 2011) plus a fixed rate of $5 \mathrm{KRW} / \mathrm{kWh}$. 
Table 4. Estimation of energy contribution from biogenic fractions in MSW.

\begin{tabular}{|c|c|c|c|c|c|c|c|}
\hline Components in MSW & Paper & Wood & Food & $\mathbf{T L}^{\mathrm{a}}$ & Plastics & Incomb. & Misc. \\
\hline wt $\%$ & 33.9 & 7.9 & 13.0 & 8.1 & 26.4 & 7.3 & 3.4 \\
\hline Biogenic fraction ${ }^{\mathrm{b}}$ & 1.0 & 1.0 & 1.0 & 1.0 & 0.0 & - & 0.0 \\
\hline LHV case $1^{\mathrm{b}}(\mathrm{MJ} / \mathrm{kg})$ & 7.07 & 10.55 & 0.93 & 14.78 & 26.31 & - & 0 \\
\hline LHV fractions $(\%)$ & 20.9 & 7.2 & 1.1 & 10.4 & 60.4 & - & 0 \\
\hline Total biogenic LHV fraction & & & & $39.6 \%$ & & & \\
\hline LHV case $2^{c}$ & 9.79 & 9.74 & 1.82 & 14.18 & 29.24 & - & 12.67 \\
\hline LHV fractions (\%) & 24.4 & 5.6 & 1.7 & 8.5 & 56.7 & - & 3.1 \\
\hline Total biogenic LHV fraction & & & & $40.2 \%$ & & & \\
\hline
\end{tabular}

Notes: ${ }^{a}$ Textile/Leather; ${ }^{\mathrm{b}}$ Data from US Energy Information Administration [32], LHV for food is annual average in Seoul [22]; ${ }^{c}$ Analytical data from Sudokwon Landfill Site, Korea, in 2000 [22].

\section{Conclusions}

The status of MSW energy recovery in Korea was reviewed and its issues related to achieving a high energy efficiency were discussed. The proportions of MSW recycled and incinerated have significantly increased to reach $60.5 \%$ and $21.6 \%$ in 2010, respectively. With a decrease in the fraction of food waste, the LHV of MSW has also gradually increased to $11.9 \mathrm{MJ} / \mathrm{kg}$. In 2010 , about half of large WtE plants were CHP while the rest produced heat alone. Heat production was dominant in the energy output due to the large demand for DH. The proportion of on-site consumption of heat and power produced was significant, but the amount of heat exported for $\mathrm{DH} / \mathrm{PH}$ and that of power to grid were gradually increasing. Although the power generation efficiency was very low, the R1 efficiency of WtE CHP plants in the country was comparable to the average of European plants. For the heat producing plants, the efficiency was higher.

To further improve energy efficiency, power generation efficiency needs to be increased by the installation of boilers with steam pressures above 20-30 bar. Transboundary centralization of WtE plants between neighboring local authorities is an essential element of waste management policy that would to prevent development of new small-scale plants with low energy efficiencies. Evaluating the renewable fraction of energy from MSW is required to promote efficient energy recovery of WtE plants and also to comply with international standards for energy statistics.

\section{Acknowledgments}

This work was supported by the Basic Science Research Program through the National Research Foundation of Korea (NRF) funded by the Ministry of Education, Science and Technology (Grant No. 2010-0006265). Thanks are also due to Kwan Seon Park (Hankook Seghers Co. Ltd.) and Young-Don Yoo (Institute for Advanced Engineering, Korea) for valuable technical data and helpful discussion on the operation and retrofit of $\mathrm{WtE}$ facilities. 


\section{References}

1. Caneghem, J.V.; Brems, A.; Lievens, P.; Block, C.; Billen, P.; Vermeulen, I.; Dewil, R.; Baeyens, J.; Vandecasteele, C. Fluidized bed waste incinerators: Design, operational and environmental issues. Prog. Energy Comb. Sci. 2012, 38, 551-582.

2. Caputo, A.C.; Pelagagge, P.M. RDF production plants: I design and costs. Appl. Therm. Eng. 2002, 22, 423-437.

3. Arena, U. Process and technological aspects of municipal solid waste gasification. A review. Waste Manag. 2012, 32, 625-639.

4. ISWA Working Group Thermal Treatment of Waste. Management of Bottom Ash from WTE Plants; International Solid Waste Association (ISWA): Copenhagen, Denmark, 2006.

5. Astrup, T. Management of APC Residues from W-t-E Plants, 2nd ed.; ISWA: Copenhagen, Denmark, 2008.

6. Monni, S. From landfilling to waste incineration: Implications on GHG emissions of different actors. Int. J. Greenh. Gas Con. 2012, 8, 82-89.

7. Eurostat. Renewable Energy Statistics. Available online: http://epp.eurostat.ec.europa.eu/ statistics_explained/index.php/Renewable_energy_statistics (accessed on 30 September 2012).

8. Energy Information Administration. Renewable Energy Annual 2009; U.S. Department of Energy: Washington, DC, USA, 2012.

9. International Energy Agency. Key World Energy Statistics 2009; International Energy Agency: Paris, France, 2009.

10. ISWA Working Group on Thermal Treatment of Waste. Energy from Waste: State-of-the-ArtReport Statistics, 5th ed.; ISWA: Copenhagen, Denmark, 2006.

11. Finney, K.N.; Sharifi, V.N.; Swithenbank, J.; Nolan, A.; White, S.; Ogden, S. Developments to an existing city-wide district energy network-Part I: Identification of potential expansions using heat mapping. Energy Convers. Manag. 2012, 62, 165-175.

12. Finney, K.N.; Chen, Q.; Sharifi, V.N.; Swithenbank, J.; Nolan, A.; White, S. Developments to an existing city-wide district energy network-Part II: Analysis of environmental and economic impacts. Energy Convers. Manag. 2012, 62, 176-184.

13. Directive 2008/98/EC of the European Parliament and the Council of 19 November 2008 on Waste and Repealing Certain Directives; Official Journal of the European Communities: Brussel, Belgium, 2008.

14. Grosso, M.; Motta, A.; Rigamonti, L. Efficiency of energy recovery from waste incineration, in the light of the new Waste Framework Directive. Waste Manag. 2010, 30, 1238-1243.

15. Statistics Korea Home Page. Available online: http://kostat.go.kr (accessed on 30 September 2012).

16. Korea New and Renewable Energy Center. New and Renewable Energy Statistics 2010 (in Korean); Korea Energy Management Corporation: Seoul, Korea, 2011.

17. Waste to Energy Strategic Plan (in Korean); Korea Ministry of Environment: Seoul, Korea, 2008.

18. National Energy Plan (2008-2030) (in Korean); Korea Prime Minister's Office: Seoul, Korea, 2008.

19. White Paper on Environment (in Korean); Korea Ministry of Environment: Seoul, Korea, 2011.

20. Eurostat Web Page. Environmental Data Center on Waste. Available online: http://epp.eurostat.ec. europa.eu/ (accessed on 30 September 2012). 
21. Korea Incineration Conference. Annual Reports on Household Wastes Incineration Facilities. Available online: http://www.k-inc.co.kr/ (accessed on 30 September 2012).

22. Ryu, C. Potential of municipal solid waste for renewable energy production and reduction of greenhouse gas emissions in South Korea. J. Air Waste Manag. Assoc. 2010, 60, 176-183.

23. Yoo, Y.D.; Yoon, Y.S.; Lee, H.H.; Shin, S.Y.; Sung, H.J.; Sung, N.G.; Hong, S.Y.; Han, I.H.; Kim, S.P.; Kim, J.H. Survey of MSW consumption (in Korean); Korea Energy Economics Institute, Ministry of Knowledge Economy: Seoul, Korea, 2012.

24. Tabasoá, A.; Kropác, J.; Kermes, V.; Nemet, A.; Stehlík, P. Waste-to-energy technologies: Impact on environment. Energy 2012, 44, 146-155.

25. Guidelines on the Interpretation of the R1 Energy Efficiency Formula for Incineration Facilities Dedicated to the Processing of Municipal Solid Waste According to Annex II of Directive 2008/98/EC on Waste; European Commission: Brussels, Belgium, 2011.

26. Park, K.S. Operation Case of Household Waste Incineration Facilities (in Korean); Korea Association of Waste to Energy Technology Autumn Workshop: Seoul, Korea, 2012.

27. Takaoka, M.; Takeda, N.; Yamagata, N.; Masuda, T. Current status of waste power generation in Japan and its impact on carbon dioxide reduction. In Proceedings of the 6th International Conference on Combustion, Incineration/Pyrolysis, Emission and Climate Change, Kuala Lumpur, Malaysia, 26-29 July 2010.

28. Hunsinger, H. A new technology for high efficient waste-to-energy plants. In Proceedings of the 6th International Conference on Combustion, Incineration/Pyrolysis, Emission and Climate Change, Kuala Lumpur, Malaysia, 26-29 July 2010.

29. Veldman, H. High efficiency energy from waste. In Proceedings of the 2nd International Conference on Biomass and Waste, Oslo, Norway, 16-17 February 2010.

30. Pavlas, M.; Touš, M.; Klimek, P.; Bébar, L. Waste incineration with production of clean and reliable energy. Clean Technol. Environ. Policy 2011, 13, 595-605.

31. Study on the Status of Waste to Energy Facilities and Efficient Energy Utilization; 11-1480000001092-01; Korea Ministry of Environment: Seoul, Korea, 2009.

32. Energy Information Administration. Methodology for Allocating Municipal Solid Waste to Biogenic and Non-Biogenic Energy; U.S. Department of Energy: Washington, DC, USA, 2007.

33. CEN EN 15440:2011 Solid Recovered Fuels-Method for the Determination of Biomass Content; European Committee for Standardization: Brussels, Belgium, 2011.

(C) 2013 by the authors; licensee MDPI, Basel, Switzerland. This article is an open access article distributed under the terms and conditions of the Creative Commons Attribution license (http://creativecommons.org/licenses/by/3.0/). 